\title{
Non-Extractive Spectrophotometric Determination of Sn(II) with 5,7-Dibromo-8-hydroxyquinoline
}

\author{
PANKAJ BHATIA*, BRIJ MOHAN, \\ ASHWANI KUMAR and HARISH KUMAR SHARMA \\ Department of Chemistry, Kurukshetra University, Kurukshetra-136119, India \\ pankajbhatia457@gmail.com
}

Received 12 April 2017 / Accepted 1 May 2017

\begin{abstract}
A non-extractive spectrophotometric method is developed for the trace determination of tin(II). The method involves the formation of yellow (1:2) coloured complex 5,7-dibromo-8hydroxyquinoline (DBHQ) in slightly acidic medium. The complex is in aqueous medium (water and ethanol solution) show absorbance at $393 \mathrm{~nm}$. The complex is stable up to 4 days. Beer's law obeyed in the range of 0-9.0 $\mu \mathrm{g} \mathrm{Sn} \mathrm{mL}^{-1}$, molar absorptivity, specific absorptivity and Sandell's sensitivity of complex are $8.133 \times 10^{4} \mathrm{~L} \mathrm{~mol}^{-1} \mathrm{~cm}^{-1}, 0.4291 \mathrm{~mL} \mathrm{~g}^{-1} \mathrm{~cm}^{-1}$ and $0.00233 \mu \mathrm{g} \mathrm{cm}{ }^{-2}$ at $393 \mathrm{~nm}$. Potential interferences have been studied. The method is free from interferences of large number of metal ions such as $\mathrm{Hg}, \mathrm{Co}, \mathrm{Mo}, \mathrm{Se}, \mathrm{Bi}, \mathrm{Cd}, \mathrm{V}, \mathrm{Re}, \mathrm{Ce}, \mathrm{W}, \mathrm{Ag}, \mathrm{Ca}, \mathrm{Be}, \mathrm{U}, \mathrm{Pt}$, Ti and other analytically important metals and anions /complexing agents. The method is quite simple, highly selective and sensitive with good reproductibility and not required any solvents for extraction. The method has been satisfactorily, by utilizing the proposed procedure; its applicability has been tested by the analysis of synthetic samples and an alloys sample of gun metal. The procedure assumes in view of the scarcity of better method for the determining tin. The results are in good agreement with certified value.
\end{abstract}

Keywords: $\mathrm{SnCl}_{2}$, DBHQ, 5,7-Dibromo-8-hydroxyquinoline

\section{Introduction}

Spectroscopic processes rely on the fact that electromagnetic radiation (EMR) interacts with atoms and molecules in discrete ways to produce characteristic absorption or emission profiles. Our own ability to perceive colour is due to the human eye acting as a detector for EMR. The property of EMR that determines the range of colour perceived is wavelength. The part of the electromagnetic spectrum that the eye can detect is known, unsurprisingly, as the visible region. The basis of spectrophotometric method is the simple relationship between the absorption of radiation by a solution and the concentration of colored species in the solution. In order to determine a species spectrophotometrically it is usually converted in to a colored complex. The color of the determinant itself is utilized much less often. 
When the determinant is not colored, or forms no colored compounds, indirect spectrophotometric methods may be used for its determination. Spectrophotometric methods are remarkable for their versatility, sensitivity and precision. Almost all are direct and can be used for all the elements, except for the noble gases. A very extensive range of concentration may be covered, from macro quantities to traces (10.2-10.8\%). Spectrophotometric methods are precise among the most of the instrumental methods of analysis.

It is the most important method for determining metals in alloys, minerals and complexes, owing to its selectivity. Since ancient times, tin has been used as a constituent of bronze. At present, it is used extensively as a coating for steel and metal cans and as an alloying element in a wide variety of metal compositions. Thus, tin occurs in trace amounts in most foods and in larger amounts in canned foods. Tin(II) fluoride, as an active agent, is also used in dental gels for the treatment of dental surfaces. However, on standing, the tin(II) in these gels is oxidized and the gels lose their activity. Thus, the determination of tin(II) in the presence of $\operatorname{tin}(\mathrm{IV})$ is of interest. In general, the total amount of tin is determined after conversion to tin(II), tin(IV) or stannane by one of the following methods: atomic absorption spectrometry ${ }^{1-7}$; fluorescence ${ }^{8}$; spectrophotometry ${ }^{9-15}$; electrochemistry ${ }^{16-18}$ and chemilumine-scence ${ }^{19}$. Tin, when present in appreciable amounts, is determined by gravimetric ${ }^{20}$, titrimetric $^{21}$ or potentiometric ${ }^{22}$ methods. A useful review of the determination of tin in the environment has been compiled by Weber ${ }^{23}$.

Of the two oxidation states, tin(II) is the least favourable for analytical usage. It is not only readily oxidized by air, but also forms basic oxides. Tin does not nature and is found almost exclusively as tin oxide known as cassiterite or tin stone. Tin although a toxic metal, still it is being widely employed in manufacturing important alloys tin occur free in has widespread use as an alloying element in the production of various alloys, for tinplating and tinning household utensils, fire warning apparatus and other safety devices, food industries, marine and automobile engines that demands simple and rapid methods for its analysis.

Spectrophotometry is essentially a trace analysis technique and is one of the most powerful tools in chemical analsis. 5,7-Dibromo-8-hydroxyquinoline (DBHQ) has been reported as a gravimetric analysis ${ }^{24}$, but has not previously been used for spectrophotometric determination of metals. This paper reports its use in a very sensitive, highly specific spectrophotometric method for trace determination of tin(II). In the present study, micro amounts of tin(II) are determined by the use of spectrophotometer.

\section{Experimental}

A UV-Visible spectrophotometer (Elico SL-177) with $10 \mathrm{~mm}$ matched cells was used for the routine absorbance measurements and spectral studies. The standard solution $(250 \mathrm{~mL})$ of tin(II $)^{10}$ containing $1 \mathrm{mg} / \mathrm{mL}$ of metal ions prepared by dissolving an accurately weight amount $(0.475 \mathrm{~g})$ of $\mathrm{Sncl}_{2} \cdot 2 \mathrm{H}_{2} \mathrm{O}$ in $20 \mathrm{~mL}$ of concentrated hydrochloric acid, diluting with de-ionized water upto the mark and standardized by the $\mathrm{SnO}_{2}$ method gravimetrically ${ }^{10}$.

Lower concentrations at $\mu \mathrm{gmL}^{-1}(10,20,30$ and 40$)$ levels prepared by suitable dilutions of this solution in hydrochloric acid. The containers of this solution were wrapped with carbon paper and kept in a dark place. Stock solutions of other metal ions were prepared at $\mu \mathrm{g} / \mathrm{mL}$ level by dissolving their commonly available pure grade sodium or potassium salts in de-ionised water or dilute acid. They were suitably diluted to give $\mu \mathrm{gmL}^{-1}$ level concentration of metal ions. 


\section{Reagents}

$0.1 \%$ 5,7-Dibromo-8-hydroxyquinoline (DBHQ) in acetone was prepared.

\section{Samples}

Synthetic samples were prepared by mixing tin solution with solutions of various metal ions in suitable proportions so as to give the composition as shown in Table 1.

\section{Gun metal}

A weighed sample of gun metal $(0.2 \mathrm{~g})$ was dissolved in $10 \mathrm{~mL}$ of concentrated hydrochloric acid and 2-4 mL of concentrated nitric acid on heating and the volume was made up to $100 \mathrm{~mL}$ in a volumetric flask. $10 \mathrm{~mL}$ of this solution was diluted to $100 \mathrm{~mL}$ to get a working solution of low concentration. An aliquot $(0.25 \mathrm{~mL})$ of this solution was analyzed by the proposed method.

\section{Procedure}

To $0.1-1.1 \mathrm{~mL}$ of slightly acidic solution containing tin(II) in a $10 \mathrm{~mL}$ calibrated flask was mixed with 5,7-dibromo-8-hydroxyquinoline followed by the addition of $0.01-1.1 \mathrm{~mL}$ of $0.05 \mathrm{~N}$ sulphuric acid. After $1 \mathrm{~min}, 5 \mathrm{~mL}$ of ethanol were added and mixture was diluted to the mark with de-ionized water. The absorption spectrum of the yellow complex with that of the blank is shown in curve-A (Figure 1). The reagent blank shown strong absorption at $360 \mathrm{~nm}$ but there was a sharp decrease in absorbance on going towards longer wavelengths and becomes negligibly small in the region $393 \mathrm{~nm}$ curve-B (Figure 1). Hence the effect of various parameters on the formation and absorbance of the complex were studied at $393 \mathrm{~nm}$.

\section{Effect of various parameters on the absorbance of $\mathrm{Sn}(\mathrm{II})-\mathrm{DBHQ}$ complex}

Different parameters affecting the complex of $\mathrm{Sn}(\mathrm{II})$-DBHQ complex. Result of these parameters is shown in Table $1.0 .1-1.1 \mathrm{~mL}$ of $(0.05 \mathrm{~N})$ sulphuric acid is optimum for the absorbance of complex. $5 \mathrm{~mL}$ Ethanol is optimum for the complex and $1 \mathrm{~mL}$ of DBHQ $(0.1 \%)$ optimum for the complex.

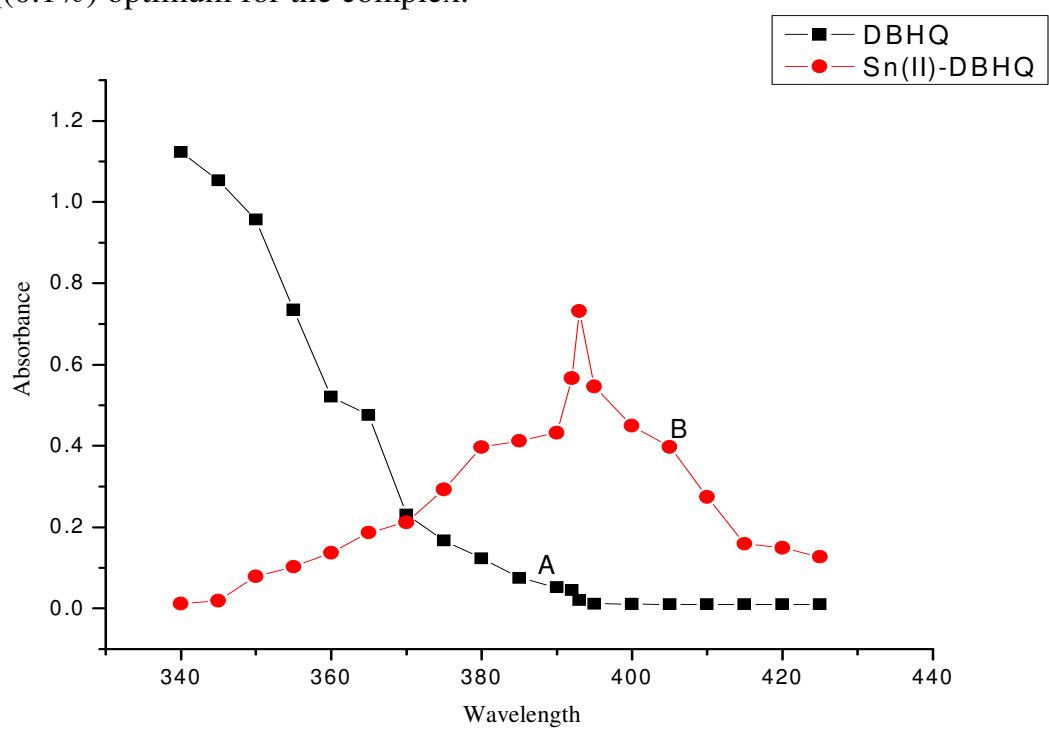

Figure 1. Electronic absorption spectra of the Sn(II)-DBHQ complex and that of the reagent blank. Curve-A the reagents blank. Curve-B Sn(II)-DBHQ against the blank (ligands). 
Table 1. Effect of various parameters on the absorbance of Sn(II)-DBHQ complex

\begin{tabular}{cccccc}
\hline $\begin{array}{c}\mathrm{H}_{2} \mathrm{SO}_{4}(0.05 \mathrm{~N}), \\
\mathrm{mL}\end{array}$ & Absorbance & $\begin{array}{c}\text { Ethanol } \\
\mathrm{mL}\end{array}$ & Absorbance & $\begin{array}{c}\text { DBHQ, 0.1\% } \\
\mathrm{mL}\end{array}$ & Absorbance \\
\hline $0.1-1.0$ & 0.732 & 2.0 & 0.235 & 0.2 & 0.287 \\
1.0 & 0.732 & 3.0 & 0.351 & 0.4 & 0.342 \\
1.5 & 0.540 & 4.0 & 0.586 & 0.8 & 0.512 \\
2.0 & 0.459 & 5.0 & 0.732 & 1.0 & 0.732 \\
2.5 & 0.429 & 6.0 & 0.527 & 1.2 & 0.435 \\
\hline
\end{tabular}

Conditions: $\mathrm{Sn}(\mathrm{II})=10 \mu \mathrm{g} ; \mathrm{H}_{2} \mathrm{SO}_{4}=$ variable; $\mathrm{DBHQ}(0.1 \%(\mathrm{~m} / \mathrm{v})$ in acetone $)=1 \mathrm{~mL}$;

Aqueous volume $=$ solvent volume $=10 \mathrm{~mL}$

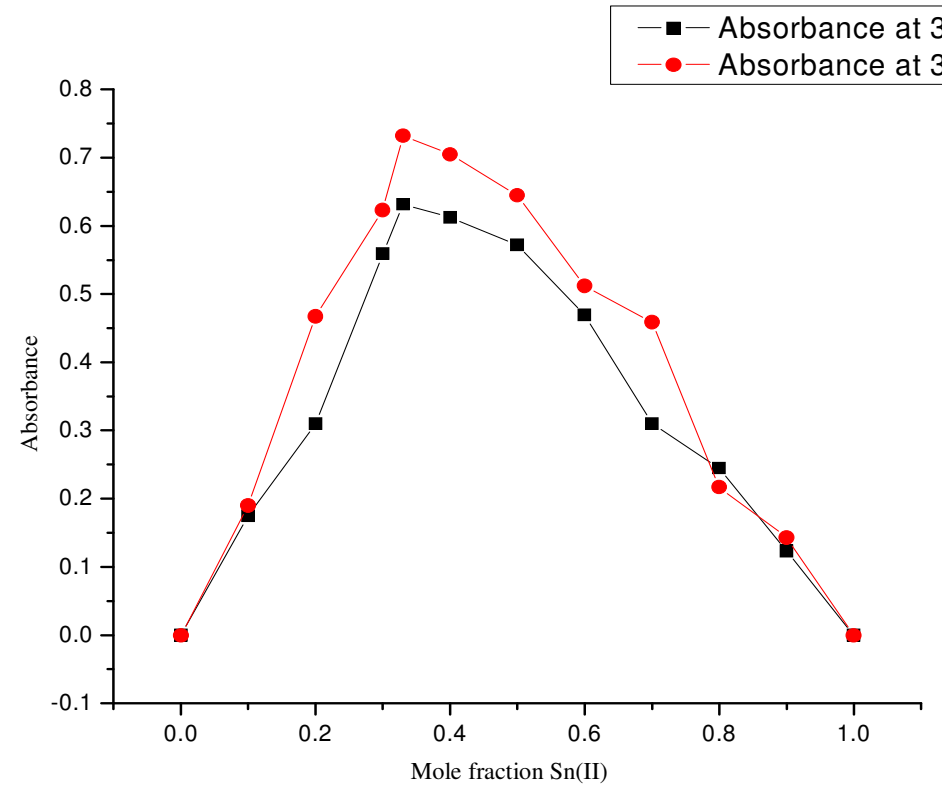

Figure 2. Job's method of continuous variations of Sn(II) and DBHQ. Absorbance (A) at 365 $\mathrm{nm}$ and (B) $393 \mathrm{~nm}$.

\section{Stoichiometry of complex}

The composition of the complex determined by Job's method of continous variations (Figure 2). Equimolar solutions of tin(II) and DBHQ were mixed and absorbance corresponding to different mole fractions of tin was measured at 365 and $393 \mathrm{~nm}$, the figure show 1:2 stoichiometry for the species. This was further confirmed by the mole ratio method and ratio is same as shown by job's method. Proposed structure is shown below in Figure 3.<smiles></smiles>

Figure 3. Proposed structure of $\left[\mathrm{Sn}(\mathrm{DBHQ})_{2}\right]$ 


\section{Effect of diverse ions}

\section{Effect of anions}

Under the optimum conditions, the effect of various anions on the Sn(II)-DBHQ complex was studied. The tolerance limit of these anions is shown in Table 2. The tolerance limit of various ions: sulphate, bromide, nitrate $(100 \mathrm{mg}$ each), iodide $(80 \mathrm{mg})$, tartate, citrate $(50 \mathrm{mg}$ each), glycerol and $\mathrm{H}_{2} \mathrm{O}_{2}(30 \% \mathrm{~W} / \mathrm{V})(1 \mathrm{~mL}$ each) etc., as shown in the Table 2.

Table 2. Effect of anions on the absorbance of Sn-DBHQ comple

\begin{tabular}{ccc}
\hline Anion added & Amount, $\mathrm{mg} / 10 \mathrm{~mL}$ & Absorbance at $393 \mathrm{~nm}$ \\
\hline Sodium eromide & 100.0 & 0.732 \\
Sodium sulphate & 100.0 & 0.732 \\
Sodium nitrate & 100.0 & 0.732 \\
Sodium iodide & 80.0 & 0.732 \\
Sodium tartate & 50.0 & 0.732 \\
Sodium citrate & 50.0 & 0.732 \\
Thiourea & 40.0 & 0.732 \\
Sulphite & 40.0 & 0.732 \\
Ascorbic acid & 20.0 & 0.732 \\
Acetate & 10.0 & 0.732 \\
Glycerol & 1.0 & 0.732 \\
$\mathrm{H}_{2} \mathrm{O}_{2}(30 \%$ W/V $)$ & 1.0 & 0.732 \\
Sodium oxalate & 0.0 & 0.567 \\
Sodium floride & 0.015 & 0.421 \\
\hline
\end{tabular}

Conditions: $\mathrm{Sn}\left(10 \mu \mathrm{g}, \mathrm{H}_{2} \mathrm{SO}_{4}=0.1-1.1 \mathrm{~mL}\right.$ of $0.05 \mathrm{~N}, 5 \mathrm{~mL}$ of ethanol, Rest is water, solvent volume $=10 \mathrm{~mL}$ Effect of cations

There are many cations which did not show any intereference in the spectrophotometric determination of $\mathrm{Tin}(\mathrm{II})$. Fe(III), $\mathrm{V}(\mathrm{V}), \mathrm{Mo}(\mathrm{VI}), \mathrm{W}(\mathrm{VI}), \mathrm{Bi}(\mathrm{III})$ and $\mathrm{Zr}(\mathrm{IV})$ and did not interfere in the presence of masking agents (Table 3).

Table 3. Analysis of samples by the proposed method

\begin{tabular}{ccc}
\hline Sample composition & $\mathrm{Sn}(\mathrm{II})$ added, $\mu \mathrm{g}$ & $\mathrm{Sn}(\mathrm{II})$ found, $\mu \mathrm{g}$ \\
\hline $\mathrm{Hg}(2.0), \mathrm{Cd}(2.0), \mathrm{U}(2.5)$ & 8 & 7.8 \\
$\mathrm{Cu}(0.5), \mathrm{Hg}(1.0)$ & 10 & 9.8 \\
$\mathrm{Re}(0.20), \mathrm{Th}(0.02), \mathrm{V}(0.05)^{\mathrm{a}}$ & 12 & 12.4 \\
$\mathrm{Cu}(0.05), \mathrm{Co}(0.025)^{\mathrm{b}}$ & 15 & 14.8 \\
$\mathrm{Zn}(1.7), \mathrm{Cu}(0.08), \mathrm{Pb}(0.6)$ & 8 & 8 \\
$\mathrm{Zn}(0.04), \mathrm{Pb}(0.02), \mathrm{Cu}(0.02)^{\mathrm{ab}}$ & 12 & 12.4 \\
$\mathrm{~Pb}(1.0), \mathrm{Fe}(0.02), \mathrm{Cu}(0.1)^{\mathrm{c}}$ & 17 & 16.8 \\
$\mathrm{Mg}(4.0), \mathrm{Cr}(5.0), \mathrm{V}(0.1)^{\mathrm{d}}$ & 8 & 7.8 \\
$\mathrm{Gun}$ metal & $4.9 \%$ & $4.5 \%$
\end{tabular}

Amount of metal shown in parentheses is in $\mathrm{mg}$, ${ }^{a}$ In the presence of $50 \mathrm{mg}$ ascorbic acid, ${ }^{a b, b}$ Corresponding to kneiss metal and argental metal corresponding. In the presence of $25 \mathrm{mg}$ ascorbic acid, ${ }^{d}$ In the presence of $20 \mathrm{mg}$ ascorbic acid

\section{Conclusion}

For the determination of microamounts of tin, the proposed method is simple, rapid, sensitive and selective and free from the interference of a large number of metal ions. The wide applicability of the method was tested by the analysis of several synthetic samples, 
tin can and gunmetal sample with satisfactory results. The high reproducibility of the method was tested by performing several sets of experiments.

\section{Conflict of interests}

The authors declare that there is no conflict of interests regarding the publication of this paper.

\section{Acknowledgment}

The authors are thankful to CSIR for providing senior research fellowship (SRF), Kurukshetra University, Kurukshetra and non-teaching staff for providing the necessary facilities.

\section{Reference}

1. Pinel R, Gandjar I G, Benabdallah M S, Astruc A and Astruc M, Analusis, 1984, 12, 404-408.

2. Ambrozio Menchola J M and Gonzales Lopez A, Rev Plast Med., 1981, 41, 550-566.

3. Matsusaki J, Meyoshi H and Takeshita R, Eisei Kagaku, 1978, 24(6), 299-303; DOI:10.1248/jhs1956.24.299

4. $\quad$ Elkins E R and Sulek A, J Assoc Off Anal Chem., 1979.62(5), 1050-1053.

5. Rigin V I, Zh Anal Khim., 1979, 34, 1564.

6. Toa H, Miyazaki A and Bansho K, Bunseki Kagaku, 1985, 34, 188.

7. Hoequettet P, At Spectrosc., 1985, 6, 69.

8. Mori I, Fujita Y and Enoki T, Bunseki Kagaku, 1976, 25, 388.

9. Taukada S, Dernura R and Yamarnoto I, Shokuhin Eiseigaku Zasshi., 1981, 22, 307.

10. Ten C C, Fenxi Huaxue, 1978, 6, 242.

11. Akirnov V K, Tenyakova L A and Antonenko L V, Zavod Lab., 1978, 44. 1047.

12. Sanz-Medel A and Carreras Gutierrez A M, Analyst, 1978, 103, 1037-1045; DOI:10.1039/AN9780301037

13. Farnsworth M and Pekola J, Anal Chem., 1954, 26(4), 735-737; DOI:10.1021/ac60088a037

14. Baranowska I, Zesz Nauk Politech Slask Chem., 1980, 633, 103.

15. Kish P P, Balog I S and Gadar S S, Ukr Khim Zh.,Russ Ed., 1987, 53, 1076.

16. Mannino S, Analyst, 1983, 108, 1257-1260; DOI:10.1039/AN9830801257

17. Alverez Sienra M A, Garcia Costa A, Tiinon Blanco P and Jerneno Arribas S, $J$ Electroanal Chem Interfacial Electrochem., 1984, 179(1-2), 201-208; DOI:10.1016/S0022-0728(84)80288-0

18. Zhang J, Yang Y andYang S, Shipin Kexeu., 1988, 104, 52.

19. Lukovskaya M M and Kushchevskaya N F, Ukr KhimZh, Russ Ed., 1985, 51, 50.

20. Farnsworth M and Pekola J, In Treatise on Analytical Chemistry, Eds., Kolthoff I M and Elving P J, Interscience, New York, 1961, 11(3), 327-368.

21. Hefferren J J, J Pharm Sci., 1963, 52, 1090.

22. Khalifa H, Abdel-Ghani N T, Issa Y M and Ibrahim H, Microchem J., 1988, 38(2), 206-210; DOI:10.1016/0026-265X(88)90022-7

23. Weber G and Fresenius Z, Anal Chem., 1985, 321(3), 217-224; DOI:10.1007/BF00470361

24. Essentials of Inorganic Chemistry, Ed., Soni P L and Kateyel M, Sultan Chand, New Delhi, 1984, 303,304. 